\title{
Frontoethmoidal meningoencephalocele: appraisal of a craniofacial surgical teaching program in Cambodia
}

\author{
Franck-Emmanuel Roux, MD, PhD, ${ }^{1-3}$ Cheng Ngiep Ou, MD, ${ }^{1}$ Ratha Soum, MD, ${ }^{1}$ \\ James Gollogly, MD, ${ }^{1}$ Imène Djidjeli, MD, ${ }^{2,3}$ and Frédéric Lauwers, MD, PhD1,2,4 \\ ${ }^{1}$ Children's Surgical Centre, Kien Khleang, Phnom Penh, Cambodia; ${ }^{2 M e ́ d e c i n s ~ d u ~ M o n d e, ~ P a r i s ; ~ a n d ~}{ }^{3}$ Neurochirurgie and \\ ${ }^{4}$ Chirurgie Maxillo-Faciale, Centre Hospitalo-Universitaire de Toulouse, Université de Toulouse, UPS, Toulouse, France
}

\begin{abstract}
OBJECTIVE The treatment of frontoethmoidal meningoencephaloceles (fMECs) in Cambodia was not possible before the development of a program that taught some Khmer surgeons (working at the Children's Surgical Centre in Phnom Penh) how to surgically correct these deformities without any foreign help. The results of that teaching program are discussed in this paper.

METHODS Between 2004 and 2009, both local and visiting foreign neurosurgical and craniofacial surgeons (the visitors coming twice a year) worked together to operate on 200 patients, and a report on those cases was published in 2010. In subsequent years (2010-2016), the Khmer surgeons operated on 100 patients without the presence of the visiting surgeons. In this study, the authors compare the second case series with the previously published series and the literature in terms of results and complications. The operations were performed with limited surgical materials and equipment, using a combined bicoronal and transfacial approach in most cases. Most of the patients came from very poor families.

RESULTS Organizing the postoperative follow-up of these low-income patients (mean age 12 years) was probably the most challenging part of this teaching program. Nine of the patients were lost to surgical follow-up. In the other cases, cosmetic results were judged by the surgeons as worse than the patient's preoperative appearance in 1 case, poor in 12 cases, average in 27 , and good in 51 -data that are significantly less encouraging than the results reported by the joint local/visiting teams in 2010 ( $p=0.0001$ ). Nevertheless, patients and parents tended to have a better overall opinion about the surgical results (rating the results as good in $84 \%$ of the 80 cases in which parent or patient ratings were available). Twenty postoperative complications were observed (the most common being temporary CSF leaks). The rate of immediate postoperative complications directly related to fMEC surgery was less than that in the previous series, but the difference was not statistically significant $(20 \%$ vs $28.5 \%, p=0.58)$. No death was noted in this case series (in contrast to the previous series). Social questionnaire results confirmed that fMEC correction partially improved the adverse social and educational consequences of fMEC in affected children.
\end{abstract}

CONCLUSIONS In the current state of this program, the local surgeons are able to correct fMECs in their own country, without foreign assistance, with good results in a majority of patients. Such humanitarian teaching programs generally take years to achieve the initial aims.

https://thejns.org/doi/abs/10.3171/2017.7.PEDS17236

KEY WORDS frontoethmoidal meningoencephalocele; Cambodia; craniofacial surgery; telecanthus

I N 2004, we initiated a program to teach Khmer surgeons how to treat frontoethmoidal meningoencephalocele (fMEC), a craniofacial malformation present in many Southeast Asian countries., ${ }^{219,20}$ There were several reasons for focusing on this disease. First, local surgeons had not been trained to treat fMEC, a malformation that we thought rather easy to treat with limited surgical resources. Second, the majority of affected persons were mentally normal ${ }^{5,8,9}$ with good functional prognoses, and once treated, the patients could hope for a radically improved social life. Third, as fMEC is reported as occurring in 1 in 5000-6000 live births,,$^{20,21}$ the frequency of this disease is rather limited; so, with around 380,000 live births per year in Cambodia (2013 WHO data; http://www.who.int/countries/khm/en/),

ABBREVIATIONS CSC = Children's Surgical Centre; $\mathrm{fMEC}=$ frontoethmoidal meningoencephalocele; $N G O=$ nongovernmental organization .

SUBMITTED May 15, 2017. ACCEPTED July 19, 2017.

INCLUDE WHEN CITING Published online December 1, 2017; DOI: 10.3171/2017.7.PEDS17236. 
around 60 new cases would be diagnosed each year. Thus, considering the possibility that not all fMECs would be amenable to surgical treatment for various reasons, it was hypothesized that fewer than 5 trained surgeons (not working exclusively on this disease, of course) could manage all the fMEC cases. Finally, when this teaching program began,$^{16}$ the combined total number of Cambodian facial surgeons and neurosurgeons in the country was less than 10 , and they also had many other diseases to treat.

For this humanitarian program, 2 features were considered fundamental. First, most affected children should ideally be treated by local surgeons, who would need to learn global management of this craniofacial malformation, including clinical evaluation, surgical treatment, and follow-up. ${ }^{13}$ Second, the aim was to treat the children free of charge, as many of them came from very poor families. A low-cost program was thus developed, with limited preand postoperative investigations and surgical infrastructure, to be run by an international nongovernmental organization (NGO), the Children's Surgical Centre (CSC), which would pay salaries to the local surgeons who would be trained in the surgical management of fMEC. ${ }^{16}$

We present here a series of 100 patients with fMEC who were operated on exclusively by Khmer surgeons between 2010 and 2016, using limited surgical materials and equipment (compared with what is available in Western institutions). This study represents the final appraisal of a humanitarian and teaching program, ${ }^{13,16,17}$ and we discuss several issues surrounding fMEC treatment that may be applicable to other surgical teaching programs in low- or middle-income countries with limited surgical resources.

\section{Methods}

Cambodia is a developing country ranking 143rd on the human poverty index of 2014 (http://hdr.undp.org/ en/countries/profiles/KHM). In 2012, 22\% of its population was reported to be living on less than $\$ 2$ a day (https://tradingeconomics.com/cambodia/poverty-gapat-national-poverty-line-percent-wb-data.html). There is a lack of local neurosurgery and reconstructive surgery teams, and even where the necessary resources and personnel are available, the costs of a craniofacial operation are prohibitive for most people. Thus, this program was devoted to surgeons working in the CSC in Phnom Penh, Cambodia - an international NGO, without political or religious affiliation, that is registered in the state of Alaska (US). It provides free ophthalmic, otologic, and reconstructive surgical care for disabled people who would not otherwise have access to the help they need. Our program also received support from Médecins du Monde (Doctors of the World), a French NGO founded in 1980 and involved in medical, surgical, psychiatric, and rehabilitation programs worldwide, which made it possible for the same team of a craniofacial surgeon, a neurosurgeon, and an anesthetist, and sometimes 1 or 2 nurses, to travel to Phnom Penh for 1-2 weeks at a time twice a year to carry out clinical work. Patient recruitment was carried out by the CSC with the assistance of the Rotary Club of Phnom Penh, which funded an outreach worker who traveled across Cambodia visiting local dispensa- ries or hospitals to find patients affected with fMEC. The teaching program was conducted during 2 time periods (2004-2009 and 2010-2016). Briefly, during the first period (2004-2009), Khmer surgeons were taught how to manage fMEC with a Western team. During the second period (2010-2016), they worked alone and the results were evaluated jointly during subsequent visits from the foreign team.

Overall, more than 200 patients with fMEC were operated on by the Khmer and Western teams during 20042009, and the results were published in 2010 as the largest surgical series on this topic to date. ${ }^{13}$ The present paper reports on the 6-year period from January 2010 through January 2016, during which local surgeons operated alone on 100 patients. None of the previous 200 surgically treated patients, whose cases were reported in our 2010 publication, ${ }^{13}$ were included in this current series of 100 "new" patients.

All treatment was free of charge from start to finish. All patients and their families signed a consent form explaining the aim of the surgery and its possible complications. This study was approved by the institutional review board of the CSC.

\section{Operative Procedure}

The operative conditions are described in detail (with photographs) in our previous article ${ }^{13}$ and were those of a general surgery center. In brief, a low-cost strategy was used for management, in which most patients received no pre- or postoperative blood tests, chest radiographs, electrocardiograms, or CT scans. Otherwise, standard operative methods and equipment, including a cautery and drills to make bur holes, were made available for these operations. No Leibinger plates or biological glue (for CSF leaks) was available. A recovery room was available, and patients were hospitalized in a large room with 16 beds.

The surgical procedure was a combined neurosurgicalcraniofacial operation performed under general anesthesia. The operation was initiated with a bicoronal incision. A frontal bone flap was then made, and the dystopic parts of the medial orbital walls were removed. The fMEC was manipulated to allow ligature of the base. This hernial dissection is considered to be the most difficult part of the neurosurgical procedure. Although dissection is performed carefully in an effort to avoid dural tears, such tears are unfortunately frequent because the dura mater is very thin in this area and adherent to the hernia base. Once ligated, the hernia was removed by suction or cautery and the proximal part was gently pushed back into the skull. A small calvarial graft was then taken from the right frontoparietal region to repair the skull base and positioned between the crista galli and the upper part of the bone flap. An epicranial patch was also used, but no surgical glue. In cases of minimal soft tissue expansion and deformity in the face, the fMEC remnants on the face were removed through the coronal incision alone to normalize facial contours. In patients with a large facial herniation, an additional facial approach to the lump was performed, taking care to obtain a minimal residual scar designed to fall into the medial canthal area and extending down to the nasolabial fold or up to the midline of the forehead. A 
medial canthopexy was performed in most of the cases, to normalize the distance between the eyes.

\section{Classification of fMECs}

The fMECs were classified according to the system described by Suwanwela and Suwanwela, ${ }^{20}$ which is based on the works of Mesterton ${ }^{11}$ and Von Meyer, ${ }^{22}$ dividing the deformity into nasofrontal, nasoethmoidal, and nasoorbital meningoencephalocoeles. More refined classifications based on CT scan findings can be used ${ }^{8}$ however, when CT scanning is not readily available, the anatomical classification of Suwanwela and Suwanwela, although less accurate, can provide an acceptable guide for managing surgical treatment.

\section{Follow-Up}

Strict conditions for follow-up were established. Each patient was entered into a database with name, address, and a phone number by which he or she could be reached. Before each operation, pictures of the patient's face (frontal, lateral, and oblique views) were taken and included in the database. Clinical follow-up appointments were scheduled for 6 months after the operation. Because travel to the CSC can be a challenge for these patients, not all patients were expected to return. In those cases in which patients did not return to the CSC for follow-up, the outreach worker attempted to contact the patients and/or their parents. In the cases in which the patients were able to return to the CSC for follow-up, new photographs were obtained at the follow-up visit for comparison with the preoperative photos, and results with respect to various clinical points were evaluated. At these follow-up visits, each patient who was operated on by the Khmer surgeons was initially evaluated by the operating surgeon and then by the Western team composed of a maxillofacial surgeon and a neurosurgeon.

\section{Evaluation}

Three criteria were used to grade the clinical results; these criteria were based on the Whitaker score used in the evaluation of the aesthetic results of surgical correction of craniosynostosis. ${ }^{23}$

1) Global aesthetic results were evaluated by the surgeons as follows. "Worse" meant that the postoperative facial appearance of the patient was worse after surgery than before. "Poor" meant that the facial appearance of the patient was not improved after surgery and was still incompatible with a normal life. "Average" meant that the facial appearance was still abnormal although improved. "Good" meant that the facial appearance was almost normal, with perhaps a few scars visible on the patient's face or minimal facial scarring, and a normal social life could be expected. In some of these cases, no one would guess that the patient had been operated on for fMEC.

2) Cosmetic results were evaluated by the patients (again, as worse, poor, average, or good). In this evaluation, patients or their parents were asked to give their opinion about the final cosmetic results of fMEC operations.

3) Finally, the social or educational "impact" of surgery was evaluated by having the children and parents answer a focused questionnaire both before the operation and at their last follow-up visit.

\section{Statistical Comparison With Previous 2010 Series}

Some results of the current study were compared with previous results from our 2010 series,${ }^{13}$ in which patients were operated on jointly by Khmer and Western surgeons. The surgical technique used was the same. It was hypothesized that the type of population and the mean age were also similar in the 2 series. Briefly, $87 \%$ of the population treated in the 2010 study were poor rural individuals, and the mean age of the 200 patients in that series was 11.6 years. Overall, 57 immediate complications directly related to fMEC surgery were noted: 24 CSF leaks, 18 skin wound infections, meningitis in 6 cases, osteomyelitis in 4 cases, hydrocephalus in 4 cases, and vision loss in 1 case. Thus, for purposes of comparison with the present series, we used a complication rate of $28.5 \%$ (57 qualifying complications in 200 operations). There were also 3 perioperative deaths. The mean length of hospitalization was 20 days. The cosmetic results were judged by the surgeons as worse in 6 cases, poor in 7, average in 27, and good in 145 of the 185 cases in which the patients returned for evaluation. Finally, fMEC surgery improved the social lives of these patients in 45 cases $(25 \%)$ according to patients' or parents' evaluations. Using Fisher tests, the type of population, mean age, complication, death rates, cosmetic results, mean hospitalization time, and improvement in social life in the 2 series were compared.

\section{Results}

There were 50 boys and 50 girls in the current series, and their mean age was 11.8 years (range 3 months-28 years, SD 6.94 years), which was similar to the age of the patients in our previous case series $(p=0.47)$. The fMECs were nasofrontal in 12 of the 100 cases, nasoethmoidal in 81 (5 left, 59 bilateral, 17 right), and naso-orbital in 3. In 3 additional cases, the fMECs were both naso-orbital and nasoethmoidal, and in the last case, the fMEC was nasofrontal and naso-orbital. Most of the associated abnormalities were ophthalmic, with a large proportion of canthal dystopias and epiphoras, as detailed in Table 1. Only 14 patients had no associated pathologies. Operations were performed via a combined bicoronal and transfacial approach in 87 cases and via a bicoronal approach alone in the remaining 13 cases. Overall, 3 surgeons were trained to manage these operations; they worked together initially

TABLE 1. Associated malformations observed in 100 surgically treated cases of $\mathrm{FMEC}$

\begin{tabular}{lc}
\hline Type of Associated Pathology & No. \\
\hline Canthal dystopia & 60 \\
\hline Epiphora (unilateral or bilateral) & 41 \\
\hline Strabismus & 20 \\
\hline Amblyopia & 12 \\
\hline Epilepsy & 3 \\
\hline Developmental delay & 2 \\
\hline
\end{tabular}




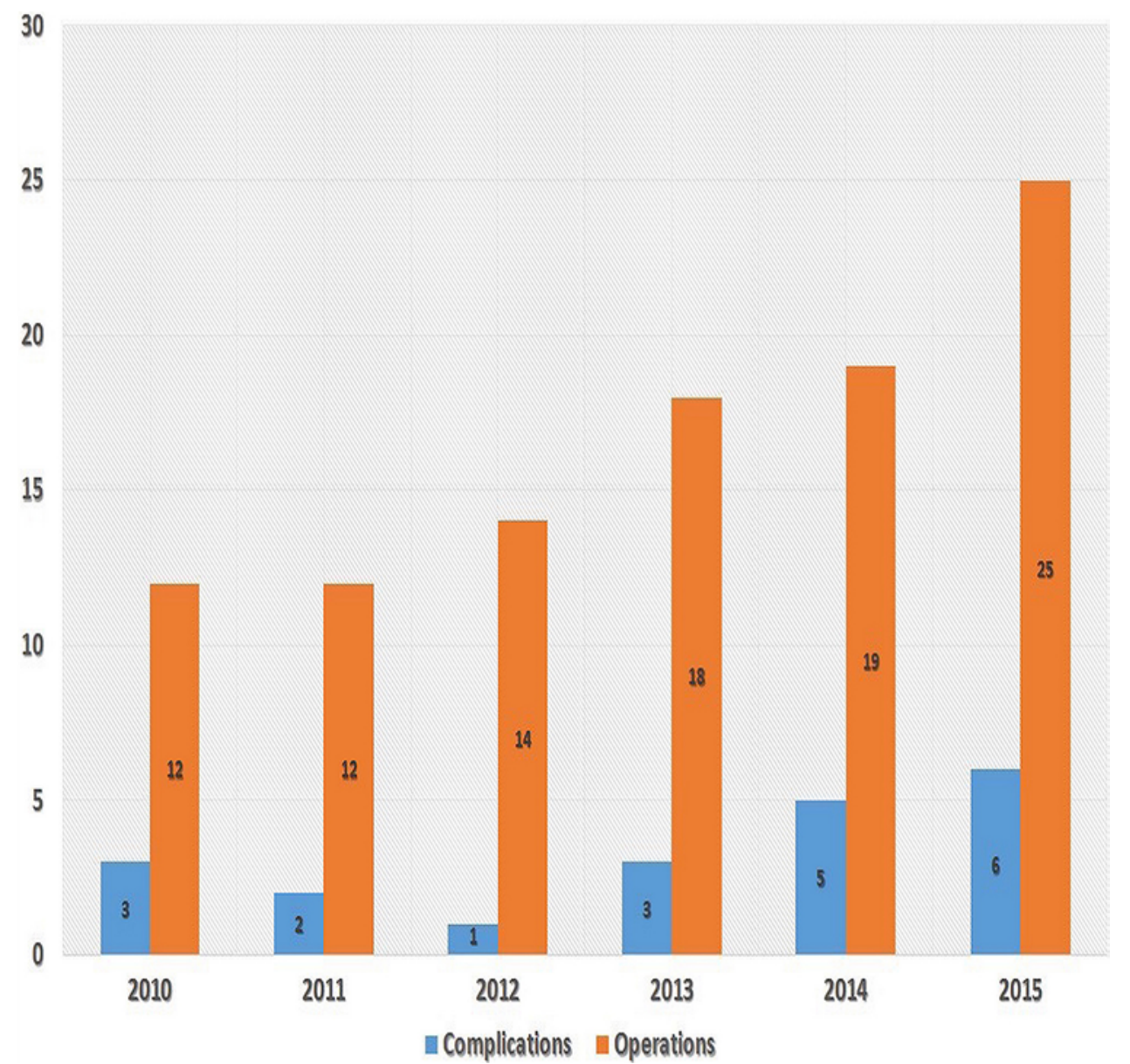

FIG. 1. Operations performed and complications. The number of fMEC operations performed between 2010 and 2016 by Khmer surgeons alone increased over the years. Overall, 20 complications were noted in this series; the number of complications also increased with the number of operations performed. Figure is available in color online only.

but began to operate individually in the last 2 years. Data available from charts did not state estimated blood losses or length of surgery. The mean duration of hospital stay was 19.66 days (range 7-49 days, SD 9.24 days), which was not significantly different $(\mathrm{p}=0.73)$ from that of the 2010 series.

\section{Family Data}

Only $51 \%$ of the final records were complete. In the other $49 \%$ of cases, one or all of the following were missing: postoperative pictures, the patient's opinion about surgery, or answers to questionnaires. Two patients were registered as orphans, and no family data were entered in 13 charts for various reasons. Of the 85 patients with recorded family data, $89 \%$ were children of farmers, as expected in this rural country; this percentage was similar to that in the 2010 series. No cases of familial fMEC were detected, and no affected children had a parent or grandparent with this malformation. The mean number of children in the families was 4.07 (range 1-12). Affected children had a mean rank in birth order of 3.6 (range 1-10, SD 1.41) although it was found that children in any rank order could be affected.

\section{Complications}

The number of operations and their complications are shown in Fig. 1 and Table 2. Overall, 20 complications were noted, with 15 patients needing 1 or more repeat op-

TABLE 2. Postoperative complications in 100 cases

\begin{tabular}{lc}
\hline \multicolumn{1}{c}{ Description } & $\begin{array}{c}\text { No. of } \\
\text { Cases }\end{array}$ \\
\hline Complications requiring additional surgical treatment & 15 \\
\hline CSF leak & 5 \\
\hline Skin/scar infection & 4 \\
\hline Hydrocephalus & 3 \\
\hline Subdural hematoma & 1 \\
\hline Scalp hematoma & 1 \\
\hline Pneumopathy requiring tracheostomy & 1 \\
\hline Complications not requiring additional surgical treatment & 5 \\
\hline Mild skin infection & 2 \\
\hline Meningitis & 1 \\
\hline Amblyopia & 2 \\
\hline
\end{tabular}


TABLE 3. Patient questionnaire: impact of surgery on social life

\begin{tabular}{|c|c|c|c|}
\hline \multicolumn{4}{|l|}{ Before the operation } \\
\hline Do you go to school? & Y & & $\mathrm{N}$ \\
\hline Are you happy to go to school? & $\mathrm{Y}$ & & $\mathrm{N}$ \\
\hline Do other children tease you now? & $\mathrm{Y}$ & & $\mathrm{N}$ \\
\hline Parents: What are your feelings about the disease of your child? & \multicolumn{3}{|c|}{ Open answer } \\
\hline \multicolumn{4}{|l|}{ After the operation (6-12 months) } \\
\hline Do you go to school? & Y & & $\mathrm{N}$ \\
\hline Are you happy to go to school? & $\mathrm{Y}$ & & $\mathrm{N}$ \\
\hline Do other children tease you now? & Y & & $\mathrm{N}$ \\
\hline Do you have more friends than before the operation? & $\mathrm{Y}$ & & $\mathrm{N}$ \\
\hline Overall, your social life or activities after the operation & Got worse & Remained the same & Improved \\
\hline What is your opinion about the results of the operation? (child when possible) & Worse & Average & Good \\
\hline What is your opinion about the results of the operation? (parents) & Worse & Average & Good \\
\hline
\end{tabular}

erations; the rate of immediate complications in the current series (calculated as number of complications divided by the number of cases) was slightly lower than that in the earlier series $(20 \%$ vs $28.5 \%)$, but the difference was not statistically significant $(\mathrm{p}=0.58)$. The most common complication seen in this series was CSF leaks, which occurred in 5 cases. These leaks were treated by direct surgical repair in 3 cases and by ventriculoperitoneal shunt insertion in 2 cases. Among the worst complications noted was bilateral blindness, which occurred in 1 patient immediately after the operation. We have no clear explanation for this complication. A CT scan performed after the operation showed no direct compression of optic nerves or chiasma (and no hydrocephalus). Damage to the optic nerves (stretching?) during this bilateral MEC repair was hypothesized. Another patient became blind in 1 eye because of infection treated late after hospital discharge. In both cases, the loss of vision appeared to be permanent. No deaths occurred in this series of 100 cases.

\section{Follow-Up}

The mean duration of follow-up was 11 months (range 1-67 months). Organizing the postoperative follow-up of patients in Cambodia was probably the most challenging part of this teaching program. In Cambodia, some patients did not have a phone at home and therefore gave the phone number of a relative or the head of their village. Furthermore, if they had a phone, they used their number for a few weeks and then changed it by changing the SIM card if another phone company made a better offer. In many cases, the patients and/or their families did not feel that any further follow-up was important after they returned home. Hence, with funding from the Rotary Club of Phnom Penh, an outreach worker was hired to visit the Cambodian countryside to bring patients back (free of charge) to the clinic or, if this was not possible, to evaluate their feelings about the surgical results and the social or educational impact of surgery by helping them to fill in the questionnaire shown in Table 3.

Answers to our 3 evaluation questions were variable.
In 9 cases, there was no aesthetic evaluation by the surgeon; in 20 cases, there was no cosmetic evaluation by the patient or parents; and 20 patients were completely lost to any social follow-up, with no further evaluation after discharge.

\section{Aesthetic and Social Results}

The aesthetic results are summarized in Table 4. Overall, using our subjective criteria as defined in Methods, the surgeons judged the cosmetic results as worse (than the preoperative appearance) in 1 case, poor in 12 cases, average in 27 cases, and good in 51 (56\%) of the 91 cases in which this evaluation was performed. Patients and parents tended to have a better overall opinion about surgical results than the surgeons did, with the result being rated as good in $67(84 \%)$ of 80 responses. Examples of pre- and postoperative photographs are shown in Fig. 2. Compared with the series of patients operated on jointly, these cosmetic results were significantly less good $(p=0.0001)$. Overall, 13 patients underwent additional facial surgery to improve the appearance of their nose between 6 months and 1 year after fMEC treatment. This revision procedure was performed by Khmer and French surgeons working together and was limited to scar improvement and small orbitonasal corrections.

Responses to questionnaire items about social life were

TABLE 4. Aesthetic results from the current series

\begin{tabular}{lcc}
\hline \multirow{2}{*}{ Result } & \multicolumn{2}{c}{ No. of Cases } \\
\cline { 2 - 3 } & Surgeon Evaluation & Patient or Parent Evaluation \\
\hline Good & 51 & 67 \\
\hline Average & 27 & 7 \\
\hline Poor & 12 & 3 \\
\hline Worse & 1 & 3 \\
\hline Data not available* & 9 & 20 \\
\hline
\end{tabular}

* The surgeon's evaluation could not be performed in 9 cases, and the patient's or parent's evaluation was not performed in 20 cases. 

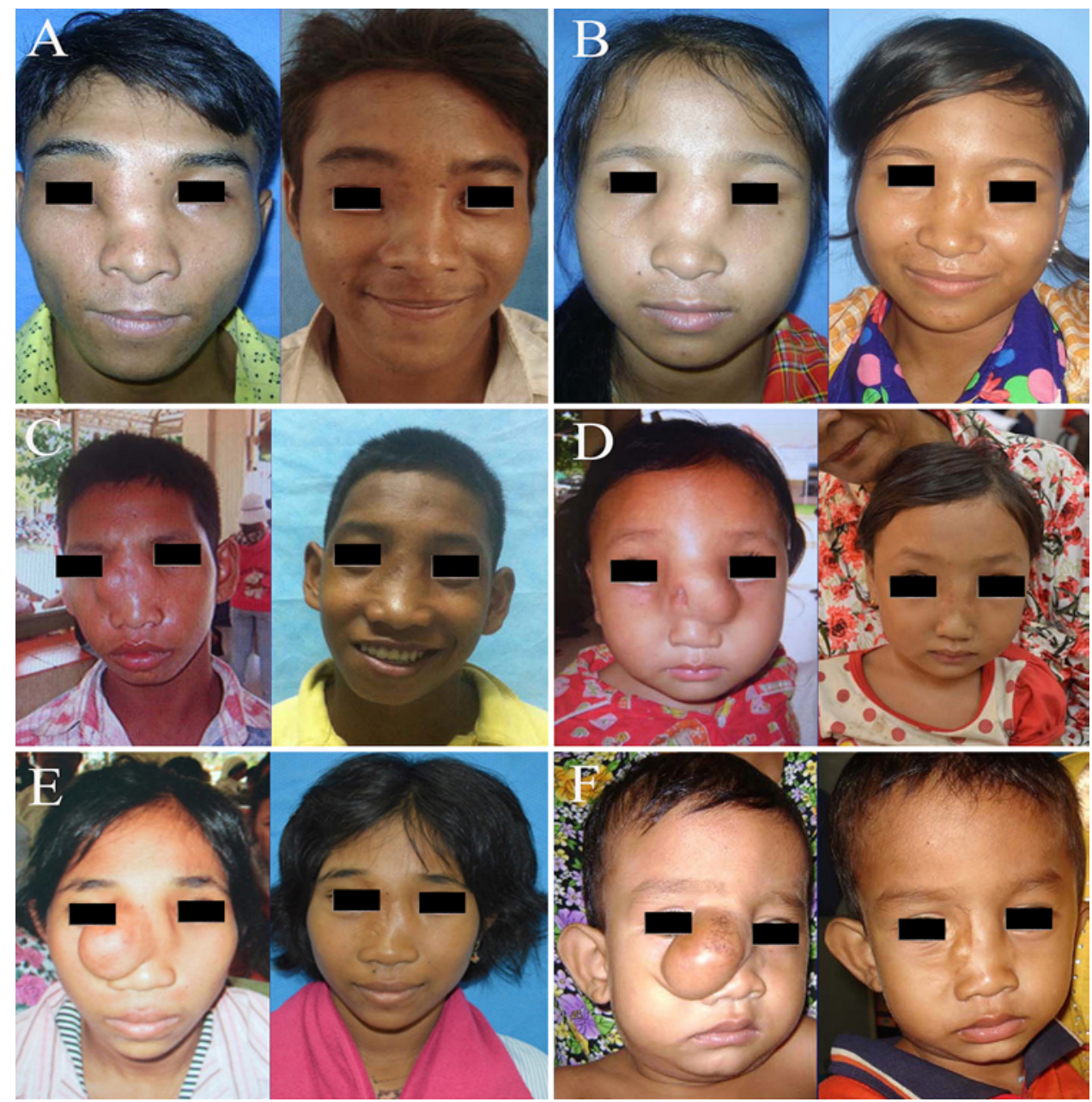

FIG. 2. Preoperative and postoperative photographs of representative patients from the current case series. A and B: Two patients in whom no facial incision was necessary and whose results were classified as good. C-F: Four patients in whom various types of facial incision were used and whose results were classified as average. Figure is available in color online only.

received from 55 patients or parents, and responses to the items concerning education were received from 49. Surgical treatment of fMEC improved the social life of these patients in 11 cases (20\%) according to patients' or parents' evaluations. In the other cases, the patients or their parents either reported that there was no change in the patients' social life or had no opinion. Two patients said that their social lives got worse, and at the time of last follow-up, 1 patient was in prison for theft. These data were not significantly different $(p=0.59)$ from the postoperative social data of the 2010 series. Access to education was better for 12 (24\%) patients of the 49 who were of school age; other children did not go to school for various reasons, such as lack of money, mockery at school, or the need to work with their parents.

\section{Costs of Each Operation}

There was no easy way to calculate the cost of 1 fMEC procedure performed by local surgeons alone at the CSC between 2010 and 2016. Our evaluation since the project started showed that around $\$ 400$ per patient was necessary for the logistics part of the process. This included all the outreach, transport, food, and clothing for the patients and, in some cases, a loss-of-earnings allowance. This allowance was rarely more than a few dollars per day but was vital in these cases to sustain the family while the patient and caregiver were away. A further $\$ 500$ per patient was necessary for the surgery, anesthesia, medicines, nursing, rehabilitation, and supplementary treatment. The total cost, including all aspects of the fMEC treatment process, was assessed at $\$ 900$ per patient.

\section{Discussion}

The results of this evaluation demonstrate that the patients in the current series, who were operated on only by Khmer surgeons trained in the earlier visits, had overall results similar to those of the patients in the 2010 series, who were operated on jointly by visiting and local surgeons. Although the aesthetic results in the current series were not as good as those for the previously published representative cases from the teaching period, in the majority of cases reported here the patients had good results. Similar hospital stays and surgery-related complications were observed, but in the current series, in contrast to previous 
series, no patients died. The results of the same questionnaire about the improvement of social life after surgery showed similar slight improvement in both series.

\section{Current Teaching Program}

Although Khmer surgeons were able to successfully operate on fMECs in Cambodia, the local surgeons should be able to improve on these results. First, in terms of aesthetic results (a rather subjective issue), the fact that none of the newly trained surgeons was a craniofacial surgeon could be one reason why their results were less favorable than in the previous series. Patients were more satisfied with their results than the surgeons, possibly because patients may have considered their free-of-charge fMEC correction to be a positive opportunity even if the results were not perfect. Without this opportunity, they would not have received any treatment at all.

The second point is that although the number of complications remained comparable to those of other series,, 13 it was higher than those for other joint teams elsewhere. ${ }^{4}$ This result could be related to the fact that the operations were not performed in a specific neurosurgical environment. As fMEC is most frequent in poor, rural people, $, 8,9,13$ it is difficult to evaluate the involvement of this specific factor in complications observed at the CSC. CSF leaks, a "direct" surgical complication, would not be related to the type of population addressed, but amblyopia caused by infection after hospital discharge is likely to be related to the remoteness of the patient from the center. The percentage of complications did not decline over time, because the surgeons trained in this program did not all begin their training at the same time. The first surgeon trained had more experience than the other 2 , who began to operate alone later. The absence of death in the current series, in contrast to the 3 deaths we experienced in the previous years, is directly related to the improvement of the immediate postoperative conditions in the recovery room (monitoring, education of nurses, no recovery room discharge before 24 hours of care).

It took many years to teach local surgeons how to do these operations, and more junior surgeons should be involved to ensure long-term treatment of fMEC in Cambodia and promote this treatment in more than 1 surgical center in the country. Nevertheless, some strong indicators of success, as defined by Ibrahim et al., ${ }^{6}$ are present in this teaching program, such as the local team being able to secure their own source of equipment. Furthermore, the surgeries were rather complex, and greater volumes were achieved in each successive year from 2011 through 2016. Decreased perioperative morbidity and complications should now be pursued.

Finally, the main challenge, lack of adequate follow-up, remains difficult to solve, as it is attributable to limited resources and lack of education in this patient population, among other factors. The basic familial data of these 100 patients matched our published epidemiological data for our previous patients ${ }^{17}$-i.e., prevalence of $\mathrm{fMEC}$ in poor families and in high rank order of pregnancy, as well as the presence of isolated cases within families - and the difficulties in performing adequate follow-up persisted within this poor population.

\section{Treatment Issues}

Frontoethmoidal MEC is almost exclusively found in low- or middle-income countries, ${ }^{17,21}$ where access to skilled neurosurgical/craniofacial surgeons and highquality treatment facilities is usually limited. The aim of surgical correction of fMEC is to achieve the best facial appearance with the least complications. In the present patient series, the cost of treating 1 child with fMEC at the CSC with surgery performed by local surgeons was estimated at about US \$900. This is much less expensive than the solution offered by some organizations of paying for selected children affected with such craniofacial malformations to be treated outside their country. The disadvantages of the latter approach include prohibitive costs that allow treatment only for very few children and lack of familiarity with the malformation and its surgical treatment among surgeons outside the affected countries. Thus, the advantages of operating on these children in modern facilities outside their country might be questionable. The money spent to treat selected children outside their country could be of benefit to many more if spent within the country. Similar issues arise for the treatment of other conditions, such as cleft lip and palate, in low- or middleincome countries. ${ }^{14}$

We believe that these children can be best treated in their country of origin. Nevertheless, there are also some concerns with this approach, centered on the surgeon, the infrastructure available locally, ${ }^{18}$ and the patients themselves. ${ }^{1}$ The main problem is that treating children in their country of origin requires a long-term effort. As shown in this paper, teaching local surgeons is an extended process. It must also be acknowledged that local surgeons do not work for free and the remuneration of local surgeons by patients with very limited financial resources is also problematic. Treating patients locally also involves a compromise between the local facilities available and the type of malformation that can be treated. In addition, recruitment of the patients can be difficult due to their lack of confidence in the medical resources of the country, their remoteness from the local surgical facilities, and their ignorance of the possibility of treatment for their pathology. This program was confronted with all these issues, and difficulties were only overcome through cooperation among organizations with different capabilities-the 3 partners, CSC, Médecins du Monde, and Rotary Club of Phnom Penh, that worked together.

\section{Basic Propositions for Humanitarian Teaching Programs}

There is a lack of neurosurgeons and infrastructure in low-income countries. ${ }^{15}$ Future planned pediatric neurosurgical missions could be centered on hydrocephalus and neural tube defects, ${ }^{10}$ which are usually difficult to treat because of the lack of trained surgeons, ${ }^{3}$ although the operations can be performed with limited surgical equipment. Moreover, the treatment of hydrocephalus by neuroendoscopy in low-income countries is an endeavor that has been underway for a relatively long time. ${ }^{12}$ Similarly, the treatment of traumatic brain injury ${ }^{7}$ is a further area that could be improved by neurosurgical teaching and knowledge sharing.

Overall, we strongly believe that success in humanitar- 
ian programs requires 1) an initial needs assessment, 2) the selection of a problem that is relatively easy to treat with limited surgical facilities, 3) patients who have a good life expectancy once the problem has been treated, 4) a patient database to be maintained to evaluate surgical results, and 5) acceptance of the fact that both foreign and local surgeons must be involved in protracted efforts over many years to achieve the initial aims.

\section{Acknowledgments}

We are indebted to the L'Oréal Foundation, which greatly helped the Médecins du Monde-Opération Sourire visiting teams at the CSC over the whole period of this program. We wish to thank the Rotary Club of Phnom Penh and its members who organized the fMEC recruitment and follow-up campaigns, the French nurses who helped us every year in these missions (Misses Fauché, Giroussens, Roux, Sanchez, and Simonnet), and Susan A. Becker for editorial assistance.

\section{References}

1. Bramall A, Djimbaye H, Tolessa C, Biluts H, Abebe M, Bernstein M: Attitudes toward neurosurgery in a low-income country: a qualitative study. World Neurosurg 82:560-566, 2014

2. Fuente del Campo A, Escanero Salazar A, Baldizon Recio N, Dimopulos A: Transfacial surgical treatment and anthropometric considerations of frontoethmoidal meningoencephaloceles. Ann Plast Surg 23:377-389, 1989

3. Funk LM, Weiser TG, Berry WR, Lipsitz SR, Merry AF, Enright AC, et al: Global operating theatre distribution and pulse oximetry supply: an estimation from reported data. Lancet 376:1055-1061, 2010

4. Holm C, Thu M, Hans A, Martina M, Silvia GS, Moritz S, et al: Extracranial correction of frontoethmoidal meningoencephaloceles: feasibility and outcome in 52 consecutive cases. Plast Reconstr Surg 121:386e-395e, 2008

5. Hoving EW, Vermeij-Keers C: Frontoethmoidal encephaloceles, a study of their pathogenesis. Pediatr Neurosurg 27:246-256, 1997

6. Ibrahim GM, Cadotte DW, Bernstein M: A framework for the monitoring and evaluation of international surgical initiatives in low- and middle-income countries. PLoS One 10:e0120368, 2015

7. Kaptigau WM, Rosenfeld JV, Kevau I, Watters DA: The establishment and development of neurosurgery services in Papua New Guinea. World J Surg 40:251-257, 2016

8. Kumar A, Helling E, Guenther D, Crabtree T, Wexler AW, Bradley JP: Correction of frontonasoethmoidal encephalocele: the HULA procedure. Plast Reconstr Surg 123:661669, 2009

9. Mahapatra AK, Agrawal D: Anterior encephaloceles: a series of 103 cases over 32 years. J Clin Neurosci 13:536-539, 2006

10. Mansouri A, Chan V, Njaramba V, Cadotte DW, Albright AL, Bernstein M: Sources of delayed provision of neurosurgical care in a rural Kenyan setting. Surg Neurol Int 6:32, 2015

11. Mesterton CB: Om medfödt hjärnbråck [dissertation]. Upsala: Upsala University, 1855
12. Muir RT, Wang S, Warf BC: Global surgery for pediatric hydrocephalus in the developing world: a review of the history, challenges, and future directions. Neurosurg Focus 41(5): E11, 2016

13. Oucheng N, Lauwers F, Gollogly J, Draper L, Joly B, Roux FE: Frontoethmoidal meningoencephalocele: appraisal of 200 operated cases. J Neurosurg Pediatr 6:541-549, 2010

14. Persing S, Patel A, Clune JE, Steinbacher DM, Persing JA: The repair of international clefts in the current surgical landscape. J Craniofac Surg 26:1126-1128, 2015

15. Qureshi MM, Piquer J, Young PH: Mobile endoscopy: a treatment and training model for childhood hydrocephalus. World Neurosurg 79:S24.e1-S24.e4, 2013

16. Roux FE, Lauwers F, Oucheng N, Say B, Joly B, Gollogly $\mathrm{J}$ : Treatment of frontoethmoidal meningoencephalocele in Cambodia: a low-cost procedure for developing countries. J Neurosurg 107 (1 Suppl):11-21, 2007

17. Roux FE, Oucheng N, Lauwers-Cances V, Draper L, Cristini $\mathrm{C}$, Collogly J, et al: Seasonal variations in frontoethmoidal meningoencephalocele births in Cambodia. J Neurosurg Pediatr 4:553-556, 2009

18. Sedney CL, Siu J, Rosseau G, Dempsey R, Bernstein M: International neurosurgical volunteerism: a temporal, geographic, and thematic analysis of foundation for international education in neurological surgery volunteer reports. World Neurosurg 82:963-968, 2014

19. Suwanwela C, Sukabote C, Suwanwela N: Frontoethmoidal encephalomeningocele. Surgery 69:617-625, 1971

20. Suwanwela C, Suwanwela N: A morphological classification of sincipital encephalomeningoceles. J Neurosurg 36:201211,1972

21. Thu A, Kyu H: Epidemiology of frontoethmoidal encephalomeningocoele in Burma. J Epidemiol Community Health 38:89-98, 1984

22. Von Meyer E: About a basal herniation in the area of lamina cribrosa. Virchows Arch Pathol Anat Physiol Klin Med 120:309-320, 1890

23. Wes AM, Paliga JT, Goldstein JA, Whitaker LA, Bartlett SP, Taylor JA: An evaluation of complications, revisions, and long-term aesthetic outcomes in nonsyndromic metopic craniosynostosis. Plast Reconstr Surg 133:1453-1464, 2014

\section{Disclosures}

The authors report no conflict of interest concerning the materials or methods used in this study or the findings specified in this paper.

\section{Author Contributions}

Conception and design: Roux, Oucheng, Soum, Gollogly, Lauwers. Acquisition of data: all authors. Analysis and interpretation of data: Roux, Djidjeli, Lauwers. Drafting the article: Roux. Critically revising the article: Roux, Gollogly, Lauwers. Reviewed submitted version of manuscript: Djidjeli.

\section{Correspondence}

Franck-Emmanuel Roux, Service de Neurochirurgie, Hôpital Purpan, Toulouse F-31059, France.email: franck_emmanuel.roux@ yahoo.fr. 